\title{
Cultivation of an Adaptive Domestic Network for Surveillance and Evaluation of Emerging Infections
}

\author{
Robert W. Pinner, Ruth Lynfield, James L. Hadler, William Schaffner, \\ Monica M. Farley, Mark E. Frank, Anne Schuchat
}

"The best time to plant a tree was 20 years ago; the second best time is now." - Chinese Proverb

$\mathrm{T}$ hrough the metaphor of an adaptive, organic entity-a tree with roots, a trunk, large limbs and smaller branches, fruits, and seeds (Figure 1) - this article describes the Emerging Infections Program (EIP), reflects on this network's accomplishments over the past 20 years, and considers opportunities and challenges for the future. Other articles in this 2015 20th anniversary issue of Emerging Infectious Diseases focusing on the EIP expand on many of the ideas introduced here, providing additional discussion, details, and references.

\section{Roots}

The concepts of emerging infectious diseases are now familiar to the scientific community and the public. However, it took a 1992 Institute of Medicine report to emphasize the dynamic and modern factors that cause infectious diseases to emerge and re-emerge and to put to rest the idea of infectious diseases as a solved problem, a worry for earlier times (1). The Centers for Disease Control and Prevention (CDC) Plan to Address Emerging Infections, released in April 1994, provided recommendations for action by CDC and other public health agencies (2). The CDC Plan highlighted the foundational role of surveillance and included in the recommendations creation of a network comprising state public health agencies, academic institutions, and CDC for special surveillance and applied public health research. The EIP sprang from these recommendations.

Even before that time, active, population-based surveillance projects dating to the 1970 s had provided a general

Author affiliations: Centers for Disease Control and Prevention, Atlanta, Georgia, USA (R.W. Pinner, M.E. Frank, A. Schuchat); Minnesota Department of Health, St. Paul, Minnesota, USA

(R. Lynfield); Yale University School of Public Health, New Haven, Connecticut, USA; (J.L. Hadler); Vanderbilt University School of Medicine, Nashville, Tennessee, USA (W. Shaffner); Emory University School of Medicine, Atlanta (M.M. Farley)

DOI: http:;//dx.doi.org/10.3201/eid2109.150619 model for the EIP. Active surveillance and related research conducted through collaborations between CDC and health departments generated information on the burden of and risk factors for toxic shock syndrome, listeriosis, Haemophilus influenzae type b (Hib) and group B Streptococcus (GBS) infections, and meningococcal disease (3-6). An earlier population-based active surveillance effort on bacterial meningitis conducted in Bernalillo County, New Mexico, provided a similar model (7). The approach-population-based, active, laboratory-based surveillance, sometimes coupled with collection of disease-causing isolates and always including key epidemiologic information - was incorporated into today's EIP activities.

Whereas earlier activities focused on a single disease or a small number of diseases and activities and operated through contracts between CDC and health departments, from the beginning the EIP dealt with multiple public health issues concurrently; engaged experts in state public health agencies, academic institutions, and a variety of CDC programs; and operated as a consortium in which stakeholders have mutual responsibilities for setting priorities, planning and executing activities, and synthesizing and communicating results $(8,9)$.

\section{Trunk}

Understanding the urgency, challenge, and complexity of its mission and the need for a flexible model to support it, the EIP built a network of collaborator sites, each contributing to shared governance, and established a strategic approach to guide projects. These elements serve as the trunk, or supportive infrastructure, for EIP efforts.

The number of sites increased-from 4 in 1994 to the current number of 10 by 2002 - as EIP activities demonstrated success, the need for broader geographic and demographic representation was recognized, and funds became available (Figure 2). EIP sites involve state health department personnel and key collaborators in academic institutions; each site engages others to conduct activities, including clinical laboratories and infection control professionals throughout each EIP area. The 10 EIP sites, together with several CDC programs and a coordinating unit 


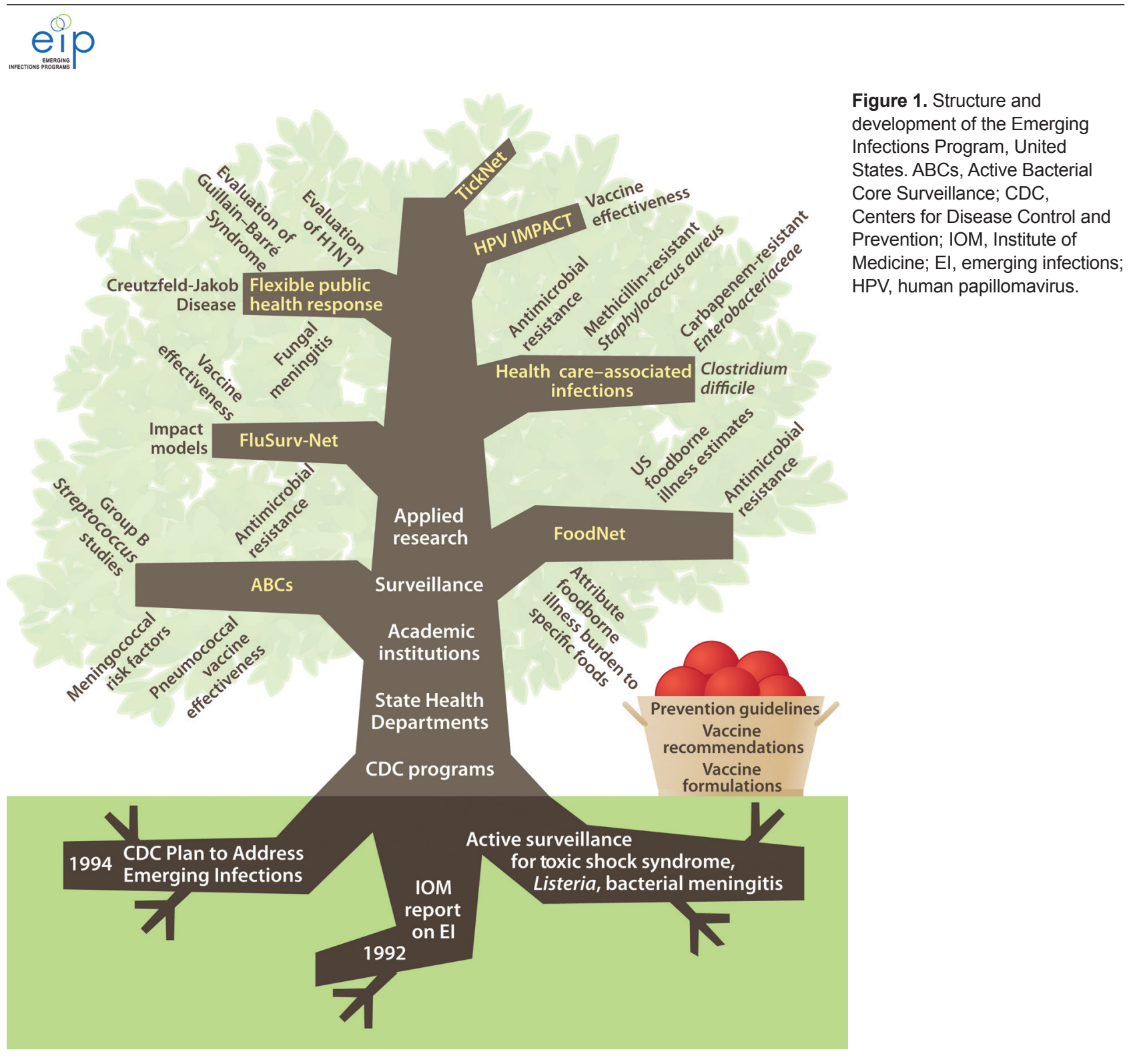

at CDC, form the EIP network. EIP support comes from core funding intended to maintain and support the network and invest in key activities. In addition, other sources support specific EIP activities. For example, funding from the US Department of Agriculture (USDA), the Food and Drug Administration (FDA), and the Food Safety Initiative of CDC have supported foodborne diseases work; the immunization program of CDC supports vaccine effectiveness evaluation and related surveillance of vaccine-preventable disease. Extramural funding for EIP cooperative agreements has ranged from $\$ 2.3$ million for 4 sites in 1995 to an average annual total of $\$ 33.8$ million for the current 10 sites during 2010-2014.

As early as the first EIP meeting in November 1994, principals at CDC and EIP sites (including representatives from state health departments and academic partners) formed an EIP Steering Group to provide guidance and strategy for
EIP activities. By the time of the Steering Group meeting in November 1996, the group had adopted guiding principles and approved a framework for evaluating ideas for new projects, which has guided assessment of potential new areas of work and strategic directions (Table).

Responsibilities and authorities are distributed across the network's membership. State public health agencies have legal authority for conducting surveillance; in this context, academic partners function as agents of the state health departments. CDC has responsibility for expending and managing federal funds invested in the EIP. Resources come from several funding streams, and each source requires accountability for ensuring that funds are spent well on appropriate activities. This distribution of responsibilities and authorities, coupled with the need for ensuring that the EIP can respond nimbly to emerging issues, has meant that governance works flexibly, not rigidly - through negotiations 
Figure 2. The Emerging Infections Program (EIP) and its key partnerships, United States. Dark shading indicates locations of EIP sites (year established are indicated in parentheses). Minnesota: Department of Health, St. Paul, and Association of Professionals in Health Control, St. Paul (1995); Oregon: Oregon Public Health Division, Portland, and Oregon Health Sciences University, Portland (1995); California: Department of Public Health, Sacramento, and University of California School of Public Health, Berkeley (1995); Colorado: Department of Public Health and Environment, Denver, and University of Colorado Health Sciences Center, Denver (2000); New Mexico: Department of Health, Santa Fe, and University of New Mexico Indian Health

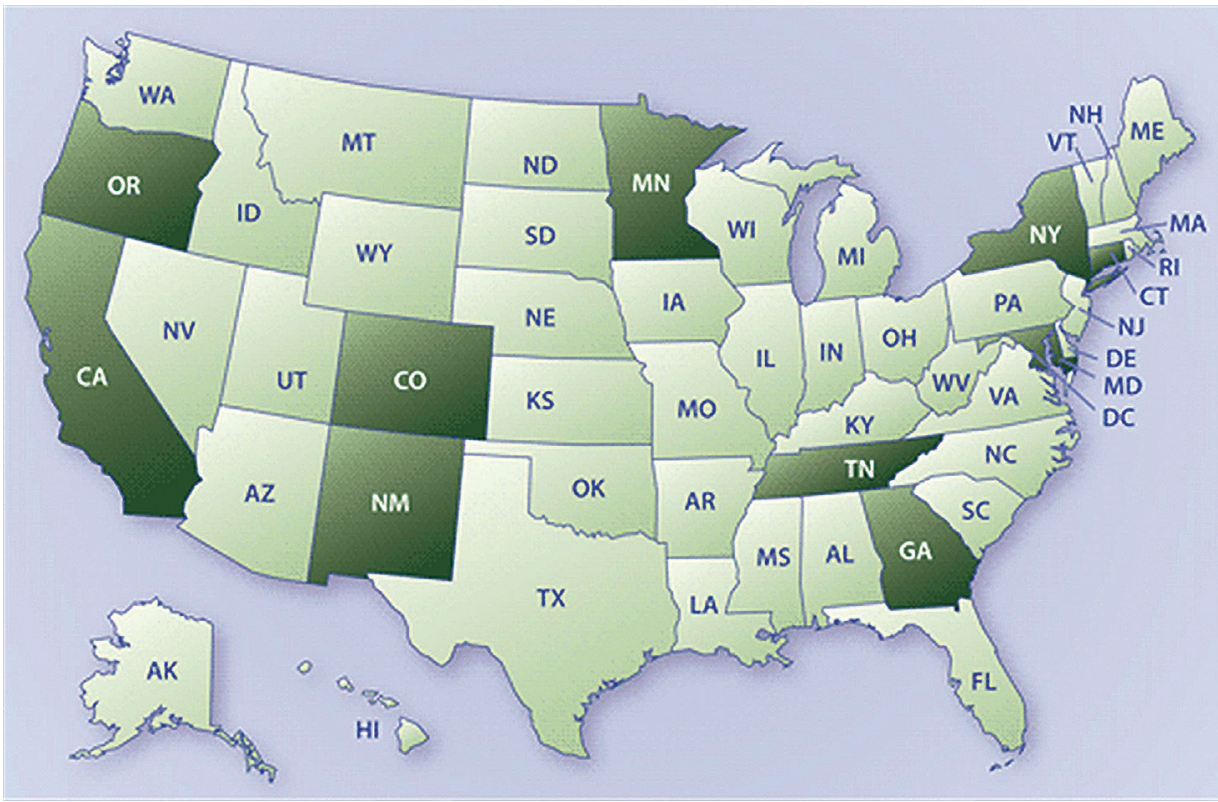
Service, Albuquerque (2002); New York: Department of Health, New York, and University of Rochester, Rochester (1997); Connecticut: Department of Public Health, Hartford, and Yale University School of Public Health, New Haven; Maryland: Department of Health and Mental Hygiene, Baltimore, University of Maryland, College Park, and Johns Hopkins University, Baltimore (1997); Tennessee: Department of Health, Nashville, and Vanderbilt University, Nashville (1999); Georgia: Department of Public Health, Atlanta, Emory University School of Medicine, Atlanta, and Atlanta Veterans Administration Medical Center, Atlanta.

and consensus - for the network as a whole and also in each project area. If one considers the distribution of interests and authorities, this model has proven productive. In addition to internal governance, EIP work has benefited from external reviews that provided advice and guidance on strategic directions, and from representatives of professional organizations (e.g., Infectious Diseases Society of America, Society for Healthcare Epidemiology of America, Council of State and Territorial Epidemiologists, American Society for Microbiology) serving on several EIP steering committees.

EIP activities generally fall into the categories of surveillance, applied research, and enhanced and flexible public health practice. Active, population-based and laboratory-based surveillance, with collection of diseasecausing isolates linked to epidemiologic information from case reports, forms the foundation of many EIP activities. This foundation accurately documents the burden of disease and key characteristics of disease-causing microbes and supports special applied research activities, such as evaluation of vaccine effectiveness and epidemiologic risk factor studies. On several occasions, the EIP has proved its flexibility and provided enhanced responses to precipitously emerging issues.

\section{Limbs and Branches}

With an established network of sites, governance, and a strategy in place, the main limbs, or programs, of the EIP grew in 4 broad thematic areas: invasive bacterial diseases; foodborne diseases; health care-associated infections; and influenza. Each program contains a portfolio of established and newer projects. Leveraging EIP resources flexibly as needed to provide fast public health responses to emerging outbreaks is a fifth limb of the EIP tree. Other branches fill out the tree.

\section{Active Bacterial Core Surveillance}

Active Bacterial Core Surveillance (ABCs) of the EIP determines the incidence and epidemiologic characteristics of invasive disease caused by bacterial pathogens, including Streptococcus pneumoniae, groups A and B Streptococcus, $H$. influenzae, Neisseria meningitidis, and Bordetella pertussis $(10,11)$. ABCs activities comprise surveillance and studies to better understand diagnostics, risk factors for disease, and vaccine effectiveness.

\section{Foodborne Diseases Active Surveillance Network}

The Foodborne Disease Active Surveillance Network (FoodNet), the principal foodborne disease component of the EIP, is a collaborative venture among the 10 EIP sites, the USDA and the FDA. This network monitors foodborne disease caused by bacterial and parasitic pathogens (Campylobacter, Cryptosporidium, Cyclospora, Listeria, and Salmonella spp.; Shiga toxin-producing Escherichia coli $\mathrm{O} 157$ and non-O157 E. coli; and Shigella, Vibrio, and Yersinia spp.) (12). 


\begin{tabular}{l} 
Table. Guiding principles for the Emerging Infections Program complied from notes of the meeting of the EIP Steering Group, \\
November $13-14,1996$, United States* \\
Guiding principles \\
EIP network is a national resource for surveillance, prevention, and control of emerging infectious diseases. EIP activities go beyond \\
the routine functions of health departments in ways that enable challenging new public health questions to be answered. \\
\hline Core EIP activities target the most pressing issues in infectious disease and are selected with regard to what is appropriate, in \\
particular, for the EIP network (including considerations such as the burden of disease, preventability, and providing resources not \\
provided through categorical funding) \\
EIP maintains sufficient flexibility for emergency response and to address new problems as they arise. \\
Training is a key function of EIP (public health students, laboratory personnel, preventive medicine residencies, infectious disease \\
fellows) \\
EIP network develops and evaluates public health practices and transfers what is learned to the public health community (e.g., \\
computerized transfer of data, molecular epidemiology, accomplishing public health work successfully in a changing health care \\
environment). \\
EIP network should give high priority to projects that lead directly to prevention of disease. \\
${ }^{*}$ EIP, Emerging Infections Program. \\
\hline
\end{tabular}

\section{Influenza Hospitalization Surveillance Network}

Through the Influenza Hospitalization Surveillance Network, the EIP, along with additional states, conducts surveillance for laboratory-confirmed influenza-related hospitalizations in children and adults (13). The influenza program at $\mathrm{CDC}$ uses this surveillance information from EIPs, together with surveillance for other aspects of influenza to develop a full annual picture of influenza and the effect of vaccination efforts in the United States.

\section{Healthcare-Associated Infections Community Interface}

The Healthcare-Associated Infections Community Interface (HAIC) investigates major and time-sensitive questions about emerging health care-associated infection (HAI) threats and antimicrobial drug resistance in the United States. The in-depth approach of the EIP to surveillance that monitors HAI diseases in health care institutions and the community and related research activities complements the broader approach used by the National Healthcare Safety Network (14).

\section{Other Branches}

Other EIP branches include earlier projects on unexplained deaths, encephalitis, hepatitis, and current TickNET and human papillomavirus (HPV) IMPACT projects (15). Surveillance to identify causes for unexplained deaths with characteristics of infectious diseases was conducted during the early years of the EIP (16). Subsequently, EIP investigators in some sites focused on the clinical challenges in diagnosing encephalitis and resultant difficulties in epidemiologic characterization, and undertook a several-year project on encephalitis. Beginning by comparing and validating several diagnostics tests, this project estimated the burden and honed characterizations of encephalitis syndromes in relation to causative agents (17). TickNET is a network of 5 EIP sites created in 2007 to foster collaboration on surveillance, research, education, and prevention for tickborne diseases. HPV IMPACT conducts a postlicensure evaluation of HPV vaccine in 5 EIP sites (18).
Flexible Responses to Emerging Issues and Outbreaks Flexibility to respond is a foundational principle for the EIP. There are several examples of the EIP's timely engagement in urgent situations.

\section{Creutzfeldt-Jakob Disease, 1996}

In 1996, an expert committee to the government of the United Kingdom recognized cases in humans of a new variant Creutzfeldt-Jakob disease (CJD) and concluded that the agent responsible for bovine spongiform encephalopathy might have spread to humans. The EIP then rapidly developed active CJD surveillance in 5 sites. This surveillance, coupled with other reviews of national CJD mortality rates, provided some assurance that the new variant CJD had not spread to the United States and helped substantiate effectiveness of death certificate reviews in identifying CJD deaths in the United States (19).

\section{Hib Vaccine Shortage, 2008}

When an Hib vaccine shortage occurred in the United States during 2008, the EIP contributed to evaluating the potential effect of deferred doses through active surveillance in the ABCs. In addition, EIP sites in Georgia and Minnesota evaluated nasopharyngeal carriage of Hib $(20,21)$.

\section{Influenza A(H1N1)pdm09, 2009}

The EIP made contributions during the influenza pandemic in 2009, not only through surveillance of hospitalizations caused by influenza but also by conducting a key evaluation of vaccine safety during the immunization campaign that year. Because of the prior association between Guillain-Barre syndrome and the 1976 vaccine against H1N1 subtype influenza virus, the EIP was engaged to conduct enhanced surveillance to estimate the magnitude of any increased risk for Guillain-Barre syndrome after administration of vaccine against influenza $\mathrm{A}(\mathrm{H} 1 \mathrm{~N} 1) \mathrm{pdm} 09$ virus. The EIP findings, that the excess risk was comparable with that associated with prior seasonal influenza vaccines and 
smaller than that observed in 1976, provided evidence for sustaining the vaccination campaign (22).

\section{Fungal Meningitis Epidemic, 2012}

Beginning in 2012, Tennessee EIP staff first detected and then provided leadership in a multistate investigation of fungal meningitis. This outbreak was caused by use of contaminated medication and resulted in 751 cases and 64 deaths across 20 states $(23,24)$.

\section{Fruits}

The EIP has borne fruit in several areas. These areas include postlicensure evaluation of vaccines, foodborne diseases, antimicrobial resistance, and health care-associated infections. The EIP has communicated its findings in nearly 1,000 publications.

\section{Vaccine Development and Policy}

The EIP has provided critical elements of the evidence base to support US immunization policy, including addressing the burden of disease, defining population groups at higher risk, evaluating cost-effectiveness of various vaccine recommendations, and determining duration of protection after widespread use. Initial recommendations for 7-valent pneumococcal conjugate vaccine (PCV7), 13-valent pneumococcal conjugate vaccine, and meningococcal conjugate $\mathrm{A} / \mathrm{C} / \mathrm{Y} / \mathrm{W}-135$ vaccines were supported by $\mathrm{ABCs}$ data, and the HPV IMPACT project provided outcome data that helped evaluate early effects of HPV vaccine implementation $(10,25,26)$. The EIP's laboratory-based surveillance and characterization of circulating strains contributed to development and recent recommendation for use of meningococcal B vaccines and group A streptococcal vaccines under development $(27,28)$.

\section{Formulating, Implementing, and Evolving an Effective Public Health Prevention Strategy against Perinatal GBS Disease}

A series of surveillance and prevention studies from $\mathrm{ABCs}$ showed the preventable burden of early-onset (GBS) infections, evaluated the relative effectiveness of initial screening vs. risk-based prevention strategies, provided assessments of prevention guidelines uptake and effect, and identified missed opportunities for additional prevention. A retrospective cohort study (10) conducted by using $\mathrm{ABCs}$ infrastructure showed that prenatal screening was $50 \%$ more effective than the risk-based strategy of directing intrapartum antimicrobial prophylaxis. These data directly resulted in revised GBS prevention guidelines by providing compelling evidence for the recommendation to implement universal prenatal GBS screening. Application of GBS prevention strategies in the era of the EIP has contributed to prevention of $\geq 85,000$ early onset GBS cases (10).

\section{Guiding and Monitoring Food Safety Efforts}

EIP FoodNet has provided standard surveillance data used by federal agencies - including the FDA, the USDA, and $\mathrm{CDC}$ - to assess national trends and progress in reducing foodborne diseases caused by bacterial and parasitic pathogens (12), especially in the context of implementing the Food Safety Initiative in 1997 and, more recently, the Food Safety Modernization Act in 2011. Studies conducted at FoodNet sites have also provided many data that contributed to estimates of the burden of foodborne pathogens in the United States in 1999 and in 2010 (12). In 1999, studies of antimicrobial drug resistance in Campylobacter spp. provided data connecting fluoroquinolone use in animals with emerging fluoroquinolone resistance in human cases of campylobacteriosis (29). The FoodNet Population Survey has produced a periodic atlas of specific food consumption prevalence in EIP sites (12). The atlas has not only provided baseline data to guide and monitor food safety educational efforts but has become a standard source of data for identifying suspect food in outbreaks caused by widely distributed foods $(9,12)$.

\section{Investigating and Responding to Antimicrobial Resistance and Health Care-Associated Infections}

Over the past 2 decades, the EIP has strengthened the evidence base regarding several antimicrobial drug-resistant pathogens. EIP projects contributed data to the CDC report on Antibiotic Resistance Threats in the United States, 2013, a widely publicized report that outlined the extent of the public health threat of antimicrobial drug resistance (30). This report helped prompt development of a National Strategy to Combat Antimicrobial Resistance in Bacteria, issued in March 2015 (14).

The EIP has studied antimicrobial drug resistance in invasive pneumococcal disease, methicillin-resistant Staphylococcus aureus (MRSA), Clostridium difficile, carbapenem-resistant Enterobacteriaceae, infections with Candida species, and patterns of antimicrobial drug use. The program documented a decrease in drug-resistant invasive pneumococcal isolates after widespread use of PCV7; emergence of resistant serotype 19A, which was not included in PCV7; and another decrease in drug-resistant pneumococcal disease after use of 13-valent pneumococcal conjugate vaccine, which included 19A $(30,31)$. Analysis of outpatient drug prescriptions and $\mathrm{ABCs}$ data found that high use of antimicrobial drugs was correlated with the proportion of nonsusceptible invasive pneumococcal disease, which suggested that local prescribing practices contribute to local drug resistance patterns (32). The EIP was instrumental in describing the emergence of community-associated MRSA (30), the burden of invasive MRSA (10), and a decrease in rates of health careassociated MRSA (33). The network determined the 
burden of infections with $C$. difficile (34) and established surveillance for carbapenem-resistant Enterobacteriaceae (35). Finally, because antimicrobial drug resistance is driven by use of these drugs, the EIP has conducted prevalence surveys to determine the frequency of infections and use of these drugs in hospitals (14).

\section{Seeds}

The EIP has planted seeds in the United States and abroad. EIP training, consultation, and collaboration activities have made substantial contributions to public health efforts.

\section{Training in the United States}

The EIP has engaged many health care professionals in training, among them numerous master's-level and doctoral-level students. These students have worked on EIP projects that have fulfilled the thesis or practicum requirement for their degree, and many have resulted in publications in peer-reviewed journals and public presentations. In addition, EIP site personnel provide scientific presentations and updates on emerging infectious diseases to local health and public health partners, and several EIP sites hold annual conferences and symposia in their regions (36).

\section{EIP-Like Activities Abroad}

Surveillance methods, study protocols, and results of EIP work have had effects around the world. An integrated infectious disease and specimen characterization surveillance system in South Africa, modeled after ABCs, has provided valuable information on invasive bacterial, diarrheal, and fungal infections and the effect of pneumococcal and Hib vaccines, and on decreasing opportunistic infections in conjunction with antiretroviral treatment among HIVinfected populations. Data from the ABCs PCV7 vaccine effectiveness study conducted when a vaccine shortage resulted in substantial numbers of children receiving $<4$ doses of vaccine provided information on partial schedules that supported licensure of 3-dose schedules in the United Kingdom and other countries. Economic analysis that incorporated indirect and direct effects of PCV, derived from EIP data, provided pivotal information for vaccine introduction decisions in countries where initial assessments, before recognition by $\mathrm{ABCs}$ investigators that there were indirect benefits, had led policy makers to conclude that the vaccine was too costly to be used routinely. The EIP model spawned International EIPs in Thailand and Kenya (37) and was adapted later to regional Global Disease Detection Centers established by CDC and ministries of health in other countries.

\section{Changes in the Climate for EIP}

Whereas weather changes often-hourly, daily, and seasonally - climate changes occur more slowly but may have profound effects. From its origins, the EIP has been in the habit of responding flexibly to the severe weather of outbreaks and emerging diseases. Now, however, the broader scientific, technological, and cultural climate in which public health agencies operate and in which emerging infections are addressed is changing substantially, requiring the EIP to adapt.

\section{Culture-Independent Diagnostic Tests and Advanced Molecular Detection}

EIP active surveillance for bacterial diseases has depended on isolation of the disease-causing organism. Case finding started in clinical laboratories, and case definitions have included isolation of an organism as part of the case definition (e.g., invasive pneumococcal disease - isolation of S. pneumoniae from a normally sterile body site). Clinical diagnoses are increasingly being made through cultureindependent diagnostic test (CIDTs), particularly nucleic acid-based tests. Although CIDTs might represent advances in modern medical practice, they can also confound EIP surveillance. Culture-independent diagnostic tests vary in their performance characteristics, and also their market share across EIP sites, which can influence incidence measurements, potentially causing discontinuity of data or requiring modeling to estimate incidence in a way that has not been previously needed. Moreover, the EIP has relied on isolates for antimicrobial drug-susceptibility testing and molecular epidemiology, which cannot be conducted-or conducted in the same way-if there are no longer clinical isolates. EIP surveillance methods, analytic methods, and case definitions will need to adapt, as will laboratory methods applied for drug susceptibility and molecular typing in EIP projects.

Even as CIDTs might challenge the continuity and quality of surveillance data, advances in laboratory technology also present new opportunities. For example, the EIP is engaged in the new advanced molecular detection (AMD) initiative at CDC to explore and advance application of modern molecular technologies to the practice of public health. With its huge asset of collections of population-based and epidemiologically well-characterized strains, the EIP is well positioned to apply AMD methods, such as whole-genome sequencing and metagenomics. As the EIP applies these powerful new tools to characterize strains and understand pathogenesis, they will enhance the quality of the network's science and contribute to the transformation of public health practice that the AMD initiative provides (38).

Information Technology and Electronic Health Records Systematic review of paper medical records by EIP surveillance officers has been central in developing high-quality information for EIP surveillance and special studies. As 
electronic health records evolve, this historical approach is disappearing and new efforts by EIP staff are required to gain appropriate and ready access to electronic records and new skills are needed to use them effectively. However, the potential for more efficient, powerful, and innovative use of modern health information technology can outweigh the problems caused by the transition from paper to electronic health records. Instead of transcribing data from charts into EIP surveillance and study forms, well-structured outputs from electronic records can save substantial staff time and resources. Also, use of structured or even ad hoc queries could make EIP surveillance and research projects more flexible and powerful. For example, EIP HAI surveillance uses queries of laboratory-automated culture and susceptibility systems to identify patterns that fit the case definition of multidrug-resistant Enterobacteriaceae. Moreover, modern geographic information systems technology offers tremendous possibilities for complementing disease surveillance with monitoring distribution of disease vectors. Recently, the EIP has identified a standard approach for geocoding cases. Adoption of this approach across EIP projects will enable researchers to connect information about cases from different EIP projects (e.g., influenza and pneumococcal pneumonia), which, when linked with other geospatial data, such as socioeconomic or climate or land use data, might help clarify underlying determinants of health and health disparities and the extent to which these pathways are similar across different diseases.

\section{Health Reform and Public Health Practice}

Health reform in the United States is affecting the way persons are obtaining health care and is also influencing the range of preventive services available, how they are delivered, and how they are funded. As the relationship between clinical care and public health evolves, there might be a role for the EIP in filling scientific gaps at the population level. The EIP could participate in assessment of the effect of health care reform on health department infectious disease control practice (e.g., evaluation of the role of health departments in direct delivery of clinical services for infectious diseases, such as immunization for tuberculosis and sexually transmitted diseases).

\section{Conclusions and New Directions}

The EIP model-close collaboration among state and federal public health agencies along with academic institutions and generation of reliable surveillance information coupled with special studies to address key policy and prevention issues that generally use a population-based approach - has provided numerous dividends for public health work in infectious diseases. The EIP tree is flourishing.

Public health issues other than infectious diseases might also benefit from the EIP model. For example, opioid overdose in the United States, with its recent epidemic-like emergence, might be one such issue. During the coming year, the EIP will explore this idea through projects at 2 sites aimed at strengthening the scientific base for prevention of opioid overdose.

A central premise of the Institute of Medicine report on emerging infections was that the emergence and reemergence of infectious diseases are a consequence of dynamic processes and factors: societal events; health care; food production; human behavior; environmental changes; public health infrastructure; and microbial adaptation $(1,2)$. Taking these factors into account, the EIP developed into a productive, flexible, and adaptive public health and scientific network. Although current circumstances differ substantially from when the network was founded, in challenges to the public's health and in tools to address them, this vision of an adaptive EIP remains apt. The aim of practicing consequential epidemiology has motivated persons who have engaged in the EIP; we hope this tenet will also guide another generation of public health professionals who will cultivate the EIP over the next 20 years (39).

\section{Acknowledgments}

We thank all persons who contributed to the work of the EIP at $\mathrm{CDC}$ and other sites; the staff at health care facilities and clinical laboratories serving the EIP catchment areas for critical contributions; authors who contributed articles for this EIP issue of the Emerging Infectious Diseases journal; EIP staff and supervisors for contributing time and effort toward training the many health care and public health students and professionals; and clinicians who referred cases to study sites; and, most importantly, patients and their families who have participated in this program.

We thank the following persons in various state EIPs for their contributions: California: Mirasol Apostol, Homayan Azizi, Susan Brooks, Erin P. Garcia, Lisa Gelling, Debra Gilliss, Carol Glaser, Deborah Godine, Margo Graves, Jill Hacker, Herschel Kirk, Mohammed Khan, Pamala Daily Kirley, Tanya Libby, Brittany Martin, Sharon McDonnell, Joelle Nadle, Sarah New, Dawn Norton, Erin Parker, Lauren Pasutti, Hallie Randel, Arthur Reingold, Maria Rosales, Gretchen Rothrock, Sue Shallow, Sam Shin, Duc Vugia, James Watt, Erin Whitney, Ashley Williamson, Lisa Winston, Jane Wong, Katie Wymore, and laboratory staff in the California Department of Public Health Microbiqal Diseases and Viral and Rickettsial Disease Laboratories; Colorado: Jessica Alicdan, Rosine Angbanzan, Deborah Aragon, Wendy Bamberg, Meghan Barnes, LaToija Black, Julianne Burke, Steve Burnite, Merida Carmona, Nicole Comstock, Amy Conroy, Nereida Corral, Shaun Cosgrove, Alicia Cronquist, Tessa Crume, Julianna Darrow, Julie Duran, Veronica Fialkowski, Matthew Finke, Ken Gershman, Laura Gillim-Ross, Ashley Grajczyk, Katelyn Hall, Lucinda Hammond, Katie Hamilton, Caleb Hedberg, Sarah Janelle, Tara 


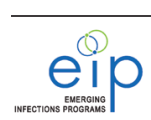

Janosz, Betsy Jarama, Helen Johnston, Ashley Juhl, Kelly Kast, Joyce Knutsen, Hugh Maguire, Kerri McClory, Lisa Miller, Julie Mullica, Maryam Nuriyeva, Stacy Page, Claire Reisenauer, Arthur Runkle, Jennifer Sadlowski, Jonathan Schwartz, Lauren Torso, Emily Travanty, Elizabeth Warfield, Blessing Wazara, Allison Wheeler, Benjamin White, Tiffany White, Elisha Wilson, Tracy Woodall, and Karen Xavier; Connecticut: Heather Altier, Lauren Backman, Robert Baltimore, Nancy Barrett, Lisa Bushnell, Matthew Cartter, Paula Clogher, Neeta Connally, Amanda Durante, Darcy Fazio, Martha Fiellin, Zack Fraser, AmberJean Hansen, Robert Heimer, Constance Heye-Smith, Kyle Higgins, Sharon Huie-White, Sharon Hurd, Pamela Julian, Stacey Kinney, Kathy Kudish, Kimberly Kunze, Carol Lyons, Patricia Macero, Ruthanne Marcus, Meghan Maloney, Ruthanne Marcus, Carmen Marquez, Vanessa McBride, James I. Meek, Richard Melchreit, Patricia Mshar, Victor Navarro, Randall Nelson, Linda Niccolai, Sara Niesobecki, Danyel Olson, John Palumbo, Andrea Perrotto, Susan Petit, Quyen Phan, Stacy Poliquin, Terry Rabatsky-Ehr, Julie Ray, Tamara Rissman, Richard Rodriguez, Roxanne Ryan, Robert W. Ryder, Andre N. Sofair, Lynn Sosa, Kristen Soto, Thomas St. Louis, Nicole Stabach, Michelle Tacariello, Suzanne Tenuta, Shirley Tirrell, Susan Smith Turner, Michael D. Virata, Tracey Weeks, Michelle Whitbread, Mark Wilson, Michelle Wilson, and Kimberly Yousey-Hindes; Georgia: Olivia Almendares, Evan Anderson, Kathryn Arnold, Wendy Baughman, Paul Blake, Chris Bower, Sandie Bulens, Victoria Catoe, Leigh Ann Clark, Charletta Cloud, Stacy Crim, Matthew Crist, Ankita Desai, Shama Desai, Cherie Drenzek, Catherine Espinosa, Elizabeth Franko, Julie Gabel, Jessica Garcia, Ryan Gierke, Jennifer Gillespie, Cindy Gross, Sasha Harb, Tameka Hayes, Dee Higgins, Virginia Hinrichsen, Amy Holst Tunali, Jamie Howgate, Lilly Immergluck, Jesse Jacob, Shabnam Jain, Matthew Johns, Tonya Johnson, Jane Kohler, Susan Lance, Lauren Lorentzson, Paul Malpiedi, Patricia Martell-Cleary, Katherine McCombs, Alicia McDonald, Rebecca Meyer, Ashley Moore, Nadine Oosmanally, Kyle Openo, May Park, Tonia Parrott, Megan Pearson, Lewis Perry, Susan Ray, Jessica Reno, Andrew Revis, David Rimland, Nicole Romero, Shaunta Rutherford, Sarah Satola, Jody Schweitzer Smith, Janine Scott, Suzanne Segler, Dolly Sharma, Zirka Smith, Danielle Smith Finch, Betsy Stein, David Stephens, Norisse Tellman Misdary, Ebony Thomas, Stephanie Thomas, Melissa Tobin-D’Angelo, Jessica Tuttle, Madhavi Vajani, Randy Van Dolson, Nancy White, Michelle Wiles, and Siri Wilson; Maryland: Brian Bachaus, Naomi Barker, Joanne Benton, Emily Blake, David Blythe, Lindsay Bonner, Michelle Boyle, Jordan Cahoon, Terresa Carter, LaToya Forrester, Malorie Givan, Lee Harrison, Rosemary Hollick, Brenna Hogan, Kim Holmes, Molly Hyde, Patricia Lawson, Rebecca Perlmutter, Mary Messenger, Maya Monroe, Katherine Richards, Heather Rutz, Patricia Ryan, Amy Sapkota, Kathleen Shutt, Elisabeth Vaeth, Vijitha Lahanda Wadu, Siok-Bi Wee, Lucy Wilson, and Helen Yoon; Minnesota:
Jennifer Adams, Joanne Bartkus, Patricia Bell-Isle, Jeff Bender, John Besser, Dave Boxrud, Larry Carroll, Elizabeth Cebelinski, Jaime Christensen, Kathy Como-Sabetti, Norman Crouch, Richard Danila, Aaron DeVries, Ginny Dobbins, Kate Engels, Patricia Ferrieri, Susan Fuller, Pam Gahr, Linda Gallatin, Anita Glennen, Annastasia Gross, Emily Hallberg, Melissa Hargreaves, Jane Harper, Kathleen Harriman, Craig Hedberg, Erin Hedican, Corinne Holtzman, Stacy Holzbauer, Liz Horn, John Hunt, Selina Jawahir, Brenda Jewell, James Johnson, Sue Johnson, Billie Juni, Dawn Kaehler, Heidi Kassenborg, Cynthia Kenyon, Mackenzie Koeck, Joe Kurland, Ellen Laine, Victoria Lappi, Fe Leano, Christine Lees, Lindsey Lesher, Catherine Lexau, Franci Livingston, Karen Martin, Kerry Macinnes, Melissa McMahon, Carlota Medus, Stephanie Meyer, Sarah Klawitter Milder, Kristine Moore, Craig Morin, Shawna Munger, Kayla Nagle, Brian Nefzger, David Neitzel, Jessica Nerby, Valerie Deneen O'Brien, Folashade Ogunmodede, Christine Olson, Rachel Ostadkar, Mike Osterholm, Kelly Pung, Jean Rainbow, Anita Ramesh, Trisha Robinson, Josh Rounds, Geraldine Salo, Amy Saupe, Joni Scheftel, Katie Schleiss, Patrick Schlievert, Kristin Shaw, Kirk Smith, Dana Soderland, Sarah Solarz, Val Solovjovs, Sara Stenzel, Anna Strain, Megan Sukalski, Katie Tastad, Charlott Taylor, Lori Triden, Sara Vetter, Paula Snippes Vagnone, Linn Warnke, Theresa Weber, Karen White, Julie Hogan Wicklund, Jason Wotton, Team Diarrhea, Team Flu, the Vector Squad, and Team ABCs, Tean C; New Mexico: Kevin Aicher, Kathy Angeles, Joseph Bareta, Marisa Bargsten, Joan Baumbach, Nathan Blacker, Lisa Bowdey, Lisa Butler, Carol Conroy, Alexander Coyle, Brooke Doman, Julianna Ferreira, Bernadette Gutierrez, Emily Hancock, Nicole Kenslow, Sarah Khanlian, Sarah Lathrop, Monear Makvandi, Robert Mansmann, Dana Moore-Smith, Lori Morrow, Megin Nichols, Cynthia Nicholson, Erin Phipps, Karen Scherzinger, David Selvage, Deborah Thompson, and Nicole West; New York: Nancy Bennett, Debra Blog, Guthrie Birkhead, Scott Brunt, Kari Burzlaff, Hwa-Gan Chang, Theresa Church, Cathleen Concannon, Salvatore Currenti, Nellie Dumas, Ghinwa Dumyati, Kay Escuyer, Rich Falco, Greg Farrell, Christina Felsen, Meghan Fuschino, Maria Gaitan, Anita Gellert, Greg Giambrone, Donna Gowie, Gary Hollick, Jillian Karr, Matt Kleabonas, Dan Kuhles, Jennifer Laplante, Denisse Licon, Suzanne McGuire, Dale Morse, Kim Musser, Geetha Nattanmai, Deborah Nelson, David Nicholas, Deven Patel, Michael Popowich, Gail Quinlan, Rama Ramani, Kim Rush-Wilson, Mary Scahill, Cynthia Schulte, Glenda Smith, Nancy Spina, Kirsten St. George, Nadia Thomas, Rebecca Tsay, Chris Waters, Bridget Whitney, Robert S. Wills, and Shelley M. Zansky; Oregon: Nasreen Abdullah, Elizabeth Baldwin, Russel Barlow, Zintars Beldavs, Hillary Booth, Genevieve Buser, Maureen Cassidy, Paul Cieslak, Margaret Cunningham, Emilio DeBess, Kate Ellingson, David Fleming, Rita Gillam, Julie Hatch, Heather Jamieson, Matthew Laidler, Robert Laing, Juventila Liko, Abiele Ariane Mangune, Lydia Mcdonald, 
Steve Moore, Karim Morey, Valerie Ocampo, John Oh, Tasha Poissant, Laura Reynolds, Diane Roy, Allison Ryan, Monika Samper, Sean Schafer, Mark Schmidt, Magdalena Kendall Scott, Beletshachew Shiferaw, Karen Stefonek, Amy Sullivan, James Tanabe, Janie Tierheimer, Ann Thomas, Jamie Thompson, John Townes, Jennifer Tujo, Meredith Vandermeer, and Collette Young; Tennessee: Adebola Ajao, Ban Allos, Patrick G. Arbogast, Selma Archer, Dominik Aronsky, Brenda Barnes, Evelyn Barnes, Brynn Berger, Karen Bloch, Effie Boothe, Tim Boyland, L. Rand Carpenter, Kecia Carroll, Lisha ConstantineRenna, Allen S. Craig, Dorothy Conners, Ann Consiglio, Matthew Crist, Corinne Davis, Annabelle de St. Maurice, John Dunn, Katie Dyer, Melinda Eady, Amanda Faulk, Lynne Fenner, Donna Francis, Katie Garman, Robb Garman, Diane Gerber, William Goins, Caroline Graber, Sandra Gray, Alice Green, Marie Griffin, Carlos G. Grijalva, Natasha Halasa, Samir Hanna, Henrietta Hardin, Sharon Hensley, Josh Hilliard, Gail Hughett, Amanda Ingram, Astride Jules, Timothy F. Jones, Marion Kainer, Meredith Kanago, Jens Krause, Lewis B. Lefkowitz, Karen Leib, Diane Levine, Mary Louise Lindegren, Leonard Lindsay, Judy Manners, Tiffanie Marcus, Lura McKnight, Marcy McMillian, Terri McMinn, Yea-Young Min, Ed Mitchel, Ashley Moore, Jackie Mounsey, Daniel Muleta, Manideepthi Pemmaraju, Joseph F. Perz, Katherine A. Poehling, Vanessa Proctor, Belinda Redd, Betsy Robinson, Jan Roulstone, Brenda Rue, Patty Sackett, Nupur Sashti, Thomas Shaffer, Mary Snowden, H. Keipp Talbot, Thomas R. Talbot, Yi-Wei Tang, Nancy Tipton, Chasiety Turner, Pat Turri, Susan Tymensky, Jessica Vakili, Debbie Varnell, Janice VonAllmen, Kim Warren, Wendi Welch, Andrew Wiese, Deborah Wojnarik, Amy Woron, laboratory staff in the Laboratory and Microbial Diseases Laboratory, and the Tennessee Department of Health State Laboratory.

We thank the following persons for their contributions: Ellen Stromdahl (US Army Institute of Public Health); Jim Jorgensen (University of Texas Health Science Center); Dale Gerding (Hines VA Hospital and Loyola University Chicago Stritch School of Medicine); W. Charles Huskins (Mayo Clinic); Philip Polgreen (University of Iowa Carver College of Medicine); Karen Becker, Wu San Chen, David Goldman, Kristin Holt, Eric Line, and Joanna Zablotsky-Kufel (US Department of Agriculture Food Safety and Inspection Service); Elisa Elliot, Heather Green, Richard Kanwal, Karl Klontz, Keith Lampel, Susan Lance, William Lanier, Patrick McDermott, Sherri McGarry, Sheila Merriweather, Marguerite Pappaioanou, Sharon Seelman, Emily Tong, Katherine Vierk, Roberta Wagner, and Beverly Wolpert (US Food and Drug Administration); and Valerie Albrecht, Olivia M. Almendares, Larry Anderson, Carmen Sofia Arriola, Johannetsy Avillan, Arati Baral, Jamie Barnes, Bernie Beall, Ben Beard, Beth Bell, Ruth Belflower, Stuart Berman, John Besser, Brad Biggerstaff, Gwen Biggerstaff, Amy Blain, Carol Bolden, Cheryl Bopp, Christopher Braden, Joseph Bresee,
Elizabeth Briere, Laura Brown, Sandra Bulens, Mary Brandt, Meghan Brett, Cynthia Canteen-Harbor, Tim Carroll, Pam Cassiday, Smita Chavan, Sandra S Chaves, Tom Chiller, Karen Chung, Thomas Clark, Angela A. Cleveland, Jessica Cohen, Amanda Cohn, Dana Cole, Sarah Collier, Laura Conn, Stacy Crim, Tony DaSilva, Kristin Delea, Tiffany D’Mello, Marc Dolan, Joseph Dunlap, Jonathan Edwards, Ryan Fagan, Amanda Faulkner, Patricia Fields, Lyn Finelli, Collette Fitzgerald, Scott Fridkin, Alicia Fry, P. Michele Futch, Susan Gantt, Aimee Geissler, Peter Gerner-Smidt, Ruth Gierke, Ryan Gierke, Elizabeth Gladstone, L. Hannah Gould, LaZetta Grier, Patricia Griffin, Scott Grytdal, Nicole Gualandi, Alice Guh, Mitchel Grenade, Nina Grossman, Tonya Habersham, Aron Hall, C. Jason Hall, Susan Hariri, Olga Henao, Rainy Henry, Michele Hlavsa, Susan Hocevar, Robert M. Hoekstra, Sarah Hook, Jennifer Huang, Kathleen Hutchins, Martha Iwamoto, Delois Jackson, Daniel Jernigan, John Jernigan, Michelle Johnson, Greg Jones, Jeffrey Jones, John Jones, Alex Kallen, Laurie Kamimoto, Maria Karlsson, Beth Karp, Chai (Sreeni) Kothagundu, Kiersten Kugeler, Randy Kuykendall, Mark Lamias, Gayle Langley, Lisa La Place, Brenda Le, Daisy Lee, Michelle Leon, Fernanda Lessa, Melissa Lewis, Wenkai Li, Brandi Limbago, Colleen Lysen, Ruth LinkGelles, Shawn R. Lockhart, David Lonsway, Jessica MacNeil, Shelley Magill, Barbara Mahon, Karunya Manikonda, Ellyn Marder, Lauri Markowitz, Rhonda Martin, Stacey W. Martin, Leonard Mayer, Laura McAllister-Hollod, Shirley McClinton, Cliff McDonald, Lesley McGee, Londell McGlone, Nancy Messonnier, Danielle Miller, Christine Miner, Rajal Mody, Matthew Moore, Jeff Morelli, Dale Morse, Yi Mu, Elisabeth Mungai, Christina Nelson, Sonja Mali Nti-Berko, Ben Park, Jean Patel, Mary E. Patrick, Ashley Paulick, Lucia Pawloski, Elizabeth Pembleton, Anna Perea, Alejandro Pérez, Joyce Peterson, Cau Dinh Pham, Ruby Phelps, Joe Piesman, Tamara Pillishvili, Tracy Pondo, Suzanne Powell, Vincent Radke, James Kamile Rasheed, Catherine Rebmann, Carrie Reed, Regan Rickert, Rosie Robateau, Elaine Scallan, Stephanie Schrag, Isaac See, Carol Selman, Jill Sharma, Kathy Siler, Donald Sharp, David Shay, Logan Sherwood, Tami Skoff, Rachel M. Smith, Nimalie Stone, Martin Steinau, Preethi Sundararaman, Robert Tauxe, Nicola Thompson, Alexandru Tocitu, Karrie-Ann Toews, Maria L. Tondella, Tatiana Travis, Elizabeth Unger, Chris Van Beneden, Antonio Vieira, Tiffany Austin Walker, Maroya Walters, Matthew Westercamp, Emily Weston, Jean Whichard, Cynthia Whitney, Ian Williams, Margaret Williams, Carolyn Wright, Jonathan Yoder, Elizabeth Zell, Shirley Zhang, and Emily Zielinski-Gutierrez (US Centers for Disease Control and Prevention).

We also thank Nicole Bond for her specific contributions to the manuscript and Joseph Alcober for providing the figure containing the tree.

Dr. Pinner is Associate Director for Surveillance, Programs, and Informatics, National Center for Emerging and Zoonotic Diseases, Centers for Disease Control and Prevention, 
Atlanta, GA. His research interests are public health surveillance, especially for infectious diseases; trends in deaths attributed to infectious diseases; and epidemiology of several bacterial and fungal diseases.

\section{References}

1. Institute of Medicine. Emerging infections: microbial threats to health in the United States. Washington (DC): National Academy Press; 1992 [cited 2015 Jun 18]. http://www.nap.edu/catalog/ 2008/emerging-infections-microbial-threats-to-health-in-theunited-states.

2. Centers for Disease Control and Prevention. Addressing emerging infectious disease threats: a prevention strategy for the United States; 1994 [cited 2015 Jun 18]. ftp://ftp.cdc.gov/pub/infectious diseases/emergplan/pdf/emergplan.pdf.

3. Wenger JD, Hightower AW, Facklam RR, Gaventa S, Broome CV. Bacterial meningitis in the United States, 1986: report of a multistate surveillance study. The Bacterial Meningitis Study Group. J Infect Dis. 1990;162:1316-23. http://dx.doi.org/10.1093/ infdis/162.6.1316

4. Schuchat A, Deaver KA, Wenger JD, Plikaytis BD, Mascola L, Pinner RW, et al. Role of foods in sporadic listeriosis. I. Case-control study of dietary risk factors. The Listeria Study Group. JAMA. 1992;267:2041-5. http://dx.doi.org/10.1001/ jama.1992.03480150047035

5. Pinner RW, Gellin BG, Bibb WF, Baker CN, Weaver R, Hunter SB, et al. Meningococcal disease in the United States-1986.

Meningococcal Disease Study Group. J Infect Dis. 1991;164:36874. http://dx.doi.org/10.1093/infdis/164.2.368

6. Reingold AL, Broome CV, Gaventa S, Hightower AW. Risk factors for menstrual toxic shock syndrome: results of a multistate case-control study. Review of Infectious Diseases. 1989;11 Suppl 1:S35-41; discussion S41-2. http://www.ncbi.nlm. nih.gov/entrez/query.fcgi?cmd=Retrieve $\& \mathrm{db}=$ PubMed\&list_ uids $=1906910 \&$ dopt $=$ Abstract

7. Fraser DW, Geil CC, Feldman RA. Bacterial meningitis in Bernalillo County, New Mexico: a comparison with three other American populations. Am J Epidemiol. 1974;100:29-34.

8. Pinner RW, Rebmann CA, Schuchat A, Hughes JM. Disease surveillance and the academic, clinical, and public health communities. Emerg Infect Dis. 2003;9:781-7. http://dx.doi.org/ 10.3201/eid0907.030083

9. Hadler J, Danila RN, Cieslak PR, Meek JI, Schaffner W, Smith KE, et al. Emerging infections programs - state health department perspective. Emerg Infect Dis. 2015;21:1510-1515.

10. Langley G, Schaffner W, Farley MM, Lynfield R, Bennett NM, Reingold A, et al. Twenty years of Active Bacterial Core Surveillance. Emerg Infect Dis. 2015;21:1520-1528.

11. Skoff T, Baumbach J, Cieslak PR. Tracking pertussis and evaluating control measures through enhanced pertussis surveillance, Emerging Infections Program, United States. Emerg Infect Dis. 2015;21:1568-1573.

12. Henao OL, Jones TF, Vugia DJ, Griffin PM. Foodborne Diseases Active Surveillance Network-2 decades of achievements, 1996-2015. Emerg Infect Dis. 2015;21:1529-1536.

13. Chaves SS, Lynfield R, Lindegren ML, Bresee J, Finelli L. The US influenza hospitalization surveillance network. Emerg Infect Dis. 2015;21:1543-1550.

14. Magill SS, Dumyati G, Ray SM, Fridkin SK. Evaluating epidemiology and improving surveillance of infections associated with health care, United States. Emerg Infect Dis. 2015; 21:1537-1542.

15. Klevens RM, Miller JT, Iqbal K, Thomas A, Rizzo EM, Hanson H, et al. The evolving epidemiology of hepatitis a in the United States: incidence and molecular epidemiology from population-based surveillance, 2005-2007. Arch Intern Med. 2010;170:1811-8. http://dx.doi.org/10.1001/archinternmed.2010.401

16. Hajjeh RA, Relman D, Cieslak PR, Sofair AN, Passaro D, Flood J, et al. Surveillance for unexplained deaths and critical illnesses due to possibly infectious causes, United States, 19951998. Emerg Infect Dis. 2002;8:145-53. http://dx.doi.org/10.3201/ eid0802.010165

17. Bloch KC, Glaser CA. Encephalitis surveillance through the Emerging Infections Program, 1997-2010. Emerg Infect Dis. 2015; 21:1562-1567.

18. Hariri S, Markowitz LE, Bennett NM, Niccolai LM, Schafer S, Bloch KC, et al. Monitoring effect of human papillomavirus vaccines in US population, Emerging Infections Program, 2008-2012. Emerg Infect Dis. 2015;21:1557-1561.

19. Centers for Disease Control and Prevention. Surveillance for Creutzfeldt-Jakob disease-United States. MMWR Morb Mortal Wkly Rep. 1996;45:665-8.

20. Thomas JD, Jackson ML, Sharma D, Mair R, Bach MC, Castillo D, et al. Haemophilus influenzae type b carriage among young children in metropolitan Atlanta in the context of vaccine shortage and booster dose deferral. Clin Vaccine Immunol. 2011;18:2178-80. http://dx.doi.org/10.1128/CVI.05254-11

21. Lowther SA, Shinoda N, Juni BA, Theodore MJ, Wang X, Jawahir SL, et al. Haemophilus influenzae type b infection, vaccination, and $H$. influenzae carriage in children in Minnesota, 2008-2009. Epidemiol Infect. 2012;140:566-74. http://dx.doi.org/ $10.1017 /$ S0950268811000793

22. Wise ME, Viray M, Sejvar JJ, Lewis P, Baughman AL, Connor W, et al. Guillain-Barre syndrome during the 2009-2010 H1N1 influenza vaccination campaign: population-based surveillance among 45 million Americans. Am J Epidemiol. 2012;175:1110-9. http://dx.doi.org/10.1093/aje/kws196

23. Kainer MA, Reagan DR, Nguyen DB, Wiese AD, Wise ME, Ward J, et al. Fungal infections associated with contaminated methylprednisolone in Tennessee. N Engl J Med. 2012;367:2194 203. http://dx.doi.org/10.1056/NEJMoa1212972

24. Centers for Disease Control and Prevention. Multistate outbreak of fungal meningitis and other infections [cited 2015 June 18]. http://www.cdc.gov/hai/outbreaks/meningitis.html

25. Advisory Committee on Immunization Practices. Preventing pneumococcal disease among infants and young children. Recommendations of the Advisory Committee on Immunization Practices (ACIP). MMWR Recomm Rep. 2000;49:1-35.

26. Nuorti JP, Whitney CG; Centers for Disease Control and Prevention. Prevention of pneumococcal disease among infants and children-use of 13-valent pneumococcal conjugate vaccine and 23-valent pneumococcal polysaccharide vaccine-recommendations of the Advisory Committee on Immunization Practices (ACIP). MMWR Recomm Rep. 2010;59:1-18.

27. Dale JB, Penfound TA, Tamboura B, Sow SO, Nataro JP, Tapia M, et al. Potential coverage of a multivalent $\mathrm{M}$ protein-based group $\mathrm{A}$ streptococcal vaccine. Vaccine. 2013;31:1576-81. http://dx.doi.org/ 10.1016/j.vaccine.2013.01.019

28. Cohn AC, MacNeil JR, Clark TA, Ortega-Sanchez IR, Briere EZ, Meissner HC, et al. Prevention and control of meningococcal disease: recommendations of the Advisory Committee on Immunization Practices (ACIP). MMWR Recomm Rep. 2013;62:1-28.

29. Smith KE, Besser JM, Hedberg CW, Leano FT, Bender JB, Wicklund JH, et al. Quinolone-resistant Campylobacter jejuni infections in Minnesota, 1992-1998. Investigation Team. N Engl J Med. 1999;340:1525-32. http://dx.doi.org/10.1056/ NEJM199905203402001

30. Fridkin SK, Cleveland AA, See I, Lynfield R. Emerging Infections Program as antimicrobial drug resistance surveillance. Emerg Infect Dis. 2015;21:1578-1581. 
31. Moore MR, Link-Gelles R, Schaffner W, Lynfield R, Lexau C, Bennett NM, et al. Effect of use of 13-valent pneumococcal conjugate vaccine in children on invasive pneumococcal disease in children and adults in the USA: analysis of multisite, populationbased surveillance. Lancet Infect Dis. 2015;15:301-9. http://dx.doi.org/10.1016/S1473-3099(14)71081-3

32. Hicks LA, Chien YW, Taylor TH Jr, Haber M, Klugman KP; Active Bacterial Core Surveillance Team. Outpatient antibiotic prescribing and nonsusceptible Streptococcus pneumoniae in the United States, 1996-2003. Clin Infect Dis. 2011;53:631-9. http://dx.doi.org/10.1093/cid/cir443

33. Kallen AJ, Mu Y, Bulens S, Reingold A, Petit S, Gershman K, et al. Health care-associated invasive MRSA infections, 2005-2008. JAMA. 2010;304:641-8. http://dx.doi.org/10.1001/ jama.2010.1115

34. Lessa FC, Mu Y, Bamberg WM, Beldavs ZG, Dumyati GK, Dunn JR, et al. Burden of Clostridium difficile infection in the United States. N Engl J Med. 2015;372:825-34. http://dx.doi.org/ 10.1056/NEJMoa1408913

35. Chea N, Bulens SN, Kongphet TT, Lynfield R, Shaw KM, Snippes PM, et al. Improved phenotypic-based definition for identifying carbapenemase producers among carbapenem-resistant Enterobacteriaceae. Emerg Infect Dis. 2015;21:1611-1616.

36. Vugia DJ, Meek JI, Danila RN, Jones TF, Schaffner W, Baumbach J, et al. Training in infectious disease epidemiology through the Emerging Infections Program sites. Emerg Infect Dis. 2015;21:1516-1519.

37. Deutscher M, Beneden CV, Burton D, Shultz A, Morgan OW, Chamany S, et al. Putting surveillance data into context: the role of health care utilization surveys in understanding population burden of pneumonia in developing countries. J Epidemiol Glob Health. 2012;2:73-81. http://dx.doi.org/10.1016/j.jegh.2012.03.001

38. Langley G, Besser J, Iwamoto M, Lessa FC, Cronquist A, Skoff TH, et al. Effect of culture-independent diagnostic tests on future Emerging Infections Program surveillance. Emerg Infect Dis. $2015 ; 21: 1582-1588$.

39. Marks JS. Epidemiology, public health, and public policy. Prev Chronic Dis. 2009;6:A134.

Address for correspondence: Robert W. Pinner, Centers for Disease Control and Prevention, 1600 Clifton Rd NE, Mailstop D59, Atlanta, GA 30329-4027, USA; email: rpinner@cdc.gov

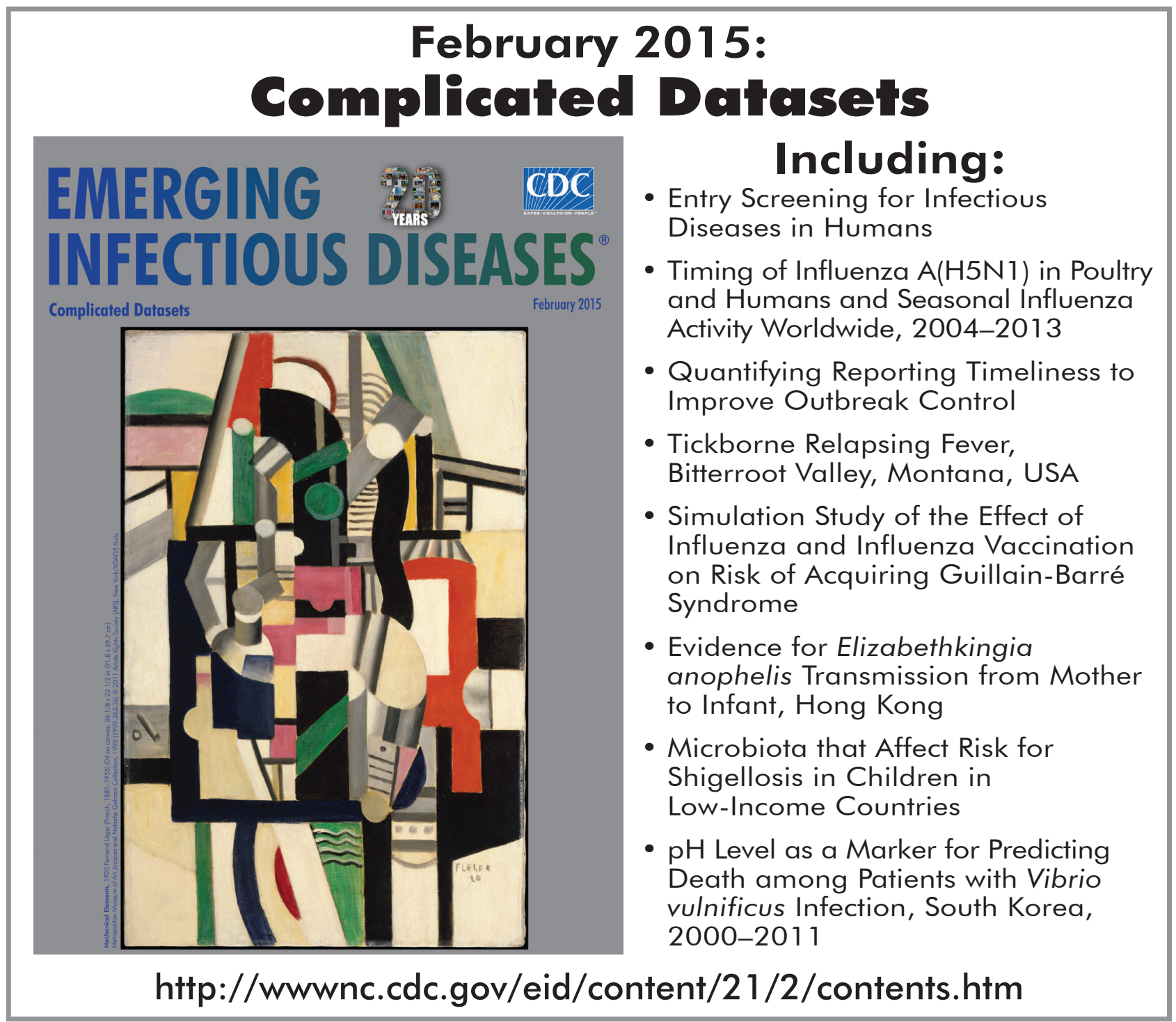

